\title{
La ruta crítica de la cibercultura mexicana
}

Octavio Islas Carmona Fernando Gutiérrez Cortés ${ }^{1}$

Se puede afirmar que la aparición de Internet constituye un parteaguas histórico que divide la comunicación humana, entre antes y después de Internet.

Ernesto Villanueva

\section{Los años maravillosos}

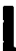

A HISTORIA DE INTERNET EN MÉXICO definitivamente no podría comprenderse sin tomar en consideración la decidida participación de algunas de las principales universidades e institutos de investigación, quienes destinaron una considerable cantidad de recursos para establecer, a finales de la década de 1980 y principios de los años noventa, los primeros enlaces dedicados a la llamada red de redes, infiriendo oportunamente la importancia que habría de alcanzar Internet en los años inmediatos.

En 1986 el Tecnológico de Monterrey, campus Monterrey ya recibía, por medio de líneas conmutadas, la información electrónica que circulaba a través de la red BITNET. En el mes de octubre de ese año, la Universidad Nacional Autónoma de México (UNAM) estableció un enlace hacia red de información electrónica. El 15 de junio de 1987, el Tecnológico de Monterrey, campus Monterrey, estableció una conexión de carácter permanente a la red BITNET.

El 28 de febrero de 1989, el Tecnológico de Monterrey, campus Monterrey, se convirtió en la primera institución en México que logró establecer un enlace dedicado a Internet, a través de una línea analógica privada de cinco hilos de 9,600 bits por segundo, conformando así el primer nodo de Internet en México.

1. Proyecto Internet del Tecnológico de Monterrey, campus Estado de México. 
Por esa sencilla razón el Tecnológico de Monterrey, campus Monterrey dispone del primer "name server" para el dominio ".mx". ${ }^{2} \mathrm{El}$ acceso a Internet que estableció el Tecnológico de Monterrey, campus Monterrey procedió de la Escuela de Medicina de la Universidad de Texas, en San Antonio (UTSA).

Por medio del Instituto de Astronomía, ubicado en la Ciudad de México, la UNAM se convirtió en la segunda institución que consiguió establecer un enlace dedicado a Internet, conformando el segundo nodo. La conexión digital a Internet se realizó vía satélite, a $56 \mathrm{Kbps}$, por el Centro Nacional de Investigación Atmosférica de Estados Unidos (NCAR), ubicado en Boulder, Colorado.

La tercera institución que estableció un enlace a Internet fue el Tecnológico de Monterrey, campus Estado de México. Tal conexión también se realizó a través del Centro Nacional de Investigación Atmosférica de Estados Unidos (NCAR). La UNAM y el Tecnológico de Monterrey, campus Monterrey entonces mantenían un enlace común por medio de la red BITNET, mediante líneas analógicas privadas.

A finales de la década de 1980, otras instituciones de educación superior y algunos de los principales centros de investigación científica infirieron las múltiples aplicaciones educativas que admitiría Internet, y realizaron considerables inversiones para establecer rutas de acceso hacia alguna de las redes de información electrónica. En tal proceso hoy es posible advertir tres grandes tendencias:

1. Instituciones de educación superior y centros de investigación que optaron por establecer su acceso a Internet a través de algún campus del Tecnológico de Monterrey o por medio de la UNAM.

2. Instituciones de educación superior y centros de investigación que decidieron establecer su enlace a Internet con alguna universidad de los Estados Unidos.

3. Instituciones educativas que optaron por establecer alguna forma de enlace a redes de información electrónica alternativas a Internet.

La Universidad de las Américas y el Instituto Tecnológico y de Estudios Superiores de Occidente (ITESO) consiguieron su enlace a Internet a través del Tecnológico de Monterrey, campus Monterrey. A pesar de que los enlaces dispuestos por esas instituciones en realidad eran de muy baja velocidad $(9,600$ bps), en tales condiciones fue posible establecer servicios de correo electrónico, transferencia de archivos (FTP) y acceso remoto (Telnet).

También a través del Tecnológico de Monterrey, campus Monterrey, se enlazaron a Internet el Colegio de Postgraduados de la Universidad de Chapin-

2. Los autores desean hacer patente su sincero agradecimiento al ingeniero Oscar Robles, responsable de NIC México, autor de una serie de relevantes notas respecto al desarrollo de Internet en México, la cual puede consultarse en las páginas electrónicas de NIC México: http:// www.nic.mx. 
go; el Centro de Investigación en Química Aplicada, ubicado en Saltillo, Coahuila, y el Laboratorio Nacional de Informática Avanzada, localizado en Xalapa, Veracruz. La Universidad de Guanajuato, ubicada en Salamanca, Guanajuato, articuló su acceso a Internet a través de la UNAM.

La Universidad de Guadalajara estableció su conexión a Internet a través de la Universidad de California en Los Ángeles (UCLA), mediante una línea privada de cuatro hilos y a una velocidad de 9,600 bps. Los primeros servicios de información electrónica que estableció la Universidad de Guadalajara en Internet inclusive se encontraban bajo el dominio de la UCLA y con direcciones IP de esa reconocida universidad de la Unión Americana.

Otras instituciones educativas optaron por establecer alguna forma de acceso a redes de información electrónica alternativas a Internet. El Instituto Tecnológico de Mexicali estableció un enlace hacia la red BESTNET. Sin embargo, el rápido desarrollo que alcanzó Internet obligó a que las instituciones educativas que habían apostado al desarrollo de redes de información electrónica alternativas a Internet, finalmente también se vieron en la necesidad de incorporarse a la llamada "red de redes", pues con el paso de los años las redes alternativas derivaron en Internet. ${ }^{3}$

A principios de la década de 1990, Red-Mex, organismo integrado por instituciones académicas, ya discutía los procedimientos que podrían regular el desarrollo de las redes de comunicación electrónica de datos en México. Ese organismo nunca logró incidir significativamente en el desarrollo de Internet en México. Por tal motivo, el 20 de enero de 1992, en la Universidad de Guadalajara se fundó Mexnet con la finalidad de coordinar los esfuerzos de las instituciones de educación superior que se encontraban interesadas en contribuir en el desarrollo de Internet en México.

En la fundación de Mexnet participaron las siguientes instituciones educativas: Universidad de Guadalajara, Tecnológico de Monterrey, Universidad de las Américas, ITESO, Colegio de Postgraduados, LANIA, CIQA, Universidad de Guanajuato, Universidad Veracruzana, Instituto de Ecología, Universidad Iberoamericana, y el Instituto Tecnológico de Mexicali.

El primero de junio de 1992, Mexnet estableció una salida digital de 56 kbps al backbone de Internet. En ese mismo año se integraron a Mexnet el Instituto Politécnico Nacional, la Universidad Autónoma Metropolitana, la Universidad Panamericana y la Universidad Autónoma de San Luis Potosí.

En 1993 se incorporaron a Mexnet la Universidad Autónoma de Nuevo León, la Universidad Autónoma de Puebla y el Instituto Tecnológico Autónomo

3. La mayor parte de las redes alternativas paulatinamente desaparecieron o se incorporaron a Internet. Esa es una de las razones por las cuales resulta tan pertinente designar a Internet como "red de redes". 
de México (ITAM). ${ }^{4}$ En ese mismo año la Universidad Autónoma Metropolitana (UAM) logró articular el primer "NAP", el cual permitió intercambiar información entre dos diferentes redes de información electrónica. ${ }^{5}$

Hasta el año de 1993 el uso de Internet en México prácticamente se restringía a aplicaciones de carácter científico y de investigación. Los principales usuarios de la gran red eran académicos e investigadores adscritos a las principales instituciones de educación superior o a institutos de investigación y, por lo general, expertos en las distintas áreas de la informática. En el periodo comprendido entre 1989 y 1993, las universidades operaron como únicos proveedores de acceso a Internet en México.

El 18 de enero de 1993, el Consejo Nacional de Ciencia y Tecnología (CONACYT) se convirtió en la primera institución pública del país que logró establecer un enlace a Internet "satelital", a través del Centro Nacional de Investigación Atmosférica (NCAR), en Boulder, Colorado. El CONACYT inmediatamente empezó a extender su red en el territorio nacional.

En 1994 se fusionaron las redes de Mexnet y CONACYT, derivándose la Red Tecnológica Nacional (RTN), la cual por medio de un enlace E-1 alcanzó 2 Mbps. También en ese mismo año, y gracias a la plena consolidación mundial de una de las principales herramientas de comunicaciones de Internet: la World Wide Web (Www), algunas empresas mexicanas realizaron los trámites necesarios para obtener los primeros dominios ".com.mx".

En el periodo comprendido entre 1994 y 1995 se creó un backbone nacional, al cual se incorporaron un mayor número de instituciones educativas, así como las primeras empresas mexicanas que optaron por definir alguna forma de acceso a Internet.

En 1995 se registró un importante incremento en el número de empresas comerciales que tramitaron dominios ".com.mx" ante NIC-México, y que lograron establecer alguna forma de acceso a Internet. El 10 de octubre de 1995, conforme a información de NIC-México, ${ }^{6}$ el número de dominios destinados a fines comerciales ascendió a cien, superando por primera vez al número de dominios ".mx" de instituciones educativas (85). El total de dominios ".mx" entonces ascendía a 211.

4. En la Península de Baja California se desarrolló una asociación relativamente similar a Mexnet: Bajared. En la creación de ese organismo sólo intervinieron instituciones educativas de la Baja California, como el Centro de Enseñanza Técnica y Superior (CETYS), Centro de Investigación Científica y Educación Superior de Ensenada (CICESE), Universidad Autónoma de Baja California (UABC), El Colegio de la Frontera Norte (COLEF) y el Instituto Tecnológico de Mexicali (ITM).

5. A finales de 1993 existían varias redes locales y regionales con acceso a Internet: MEXnet, Red UNAM, Red ITESM, RUTyC, - la cual desapareció ese mismo año-, BAJAnet, Red Total CONACYT, y SIRACYT. Esta última pretendió agrupar todas las redes.

6. Véase: ftp://ftp.nic.mx/pub/history.txt. 
Ese hecho en realidad definiría el inicio de una nueva etapa en el desarrollo de Internet en México, en la cual los proveedores de acceso y las empresas nacionales y multinacionales que incursionaron en los mercados emergentes de Internet, habrían de asumir un mayor control sobre el desarrollo de Internet en México.

En diciembre de 1995 se anunció la creación del Centro de Información de Redes de México - Network Information Center de México-, institución que se encargaría de administrar y coordinar el desarrollo de los recursos de Internet en México. La administración de NIC-México - por lógicas razones históricasse otorgó al Tecnológico de Monterrey, campus Monterrey. Una de las principales funciones de NIC-México es asignar y administrar los dominios ".mx".

Algunas empresas dedicadas a comercializar servicios de Internet con cierta insistencia han objetado las tareas que desempeña el Tecnológico de Monterrey en la administración de los recursos de Internet en México, a través de NIC-México, argumentando que por tratarse de una institución educativa, ésta inhibe las posibilidades de realizar un mayor número de negocios a través de Internet.

En un futuro inmediato, dada la importancia que habrá de adquirir el desarrollo del "comercio electrónico", 7 seguramente se intensificarán las objeciones hacia el Tecnológico de Monterrey. Respecto al sentido de tales críticas, es preciso entender que cualquier institución educativa que pudiese obstruir los intereses de las grandes empresas nacionales y multinacionales dedicadas a realizar negocios relacionados con Internet, seguramente sería blanco de cuestionamientos similares.

7. Moira Jacobs, responsable directa de más de 100 centros que proporcionan servicios integrales de consultoría en materia de Internet y comercio electrónico a las empresas estadounidenses interesadas en exportar, dependientes del Departamento de Comercio de Estados Unidos, señala que la firma Forester Research estima que en el año 2003, las ventas que habrán de realizarse por Internet representarán utilidades por 3.2 trillones de dólares. Moira Jacobs presentó la ponencia "International E-Business Oportunities and Challenges: A Small Business Perspective", en "The 1999 e-Business Opportunities, Challenges, and Winning Strategies". El referido congreso fue organizado por la Universidad de Montana en Missoula y The Montana World Trade Center. Missoula, Montana, Estados Unidos, 2 al 5 de agosto de 1999. 


\section{El fin de la inocencia}

La ecología de la información ha crecido en forma impresionante, y ha estimulado y reconfigurado simultáneamente a la diversidad, creando puntos de contacto y comunicación antes inexistentes. La percepción aparece así en forma más compleja y cubriendo una porción grande del espacio social de forma horizontal. Este es el momento de reconocer nuevas comunidades en nuevas ecologías informáticas y de comunicación. El espacio social se renueva y se conecta, la mente ecológica se complejiza y expande.

Jesús Galindo ${ }^{8}$

En 1995 el sector público manifestaba absoluta indiferencia por el desarrollo de Internet en México. Es posible afirmar que amplio número de funcionarios públicos suponía que Internet era un recurrente tema de la literatura de ciencia ficción.

Como ejemplo del pobre interés que manifestaba la administración del presidente Ernesto Zedillo por asuntos relativos al tema de Internet, ${ }^{9}$ basta referir que el "Programa de Desarrollo Informático", elaborado por la Academia Nacional de la Informática, y derivado del "Plan Nacional de Desarrollo", no sólo no contempló ninguna estrategia concreta por parte del Estado en materia de Internet: como si se tratase de una palabra prohibida, el referido plan ni siquiera consignó la palabra Internet. ${ }^{10}$

La mayor parte del personal que laboraba en la Dirección General de Comunicación Social de la Presidencia de la República (1995) realizaba sus labores ordinarias empleando viejas máquinas de escribir -ignoramos si ello ha cambiado. La mayoría de los funcionarios responsables de las distintas direcciones ignoraban la existencia de Internet y también, por supuesto desconocían el intenso proselitismo internacional que ya realizaban los simpatizantes del Ejército Zapatista de Liberación Nacional (EZLN) en el ciberespacio.

Desde la primavera de 1994, el profesor Jaustin Paulson, miembro del Consejo de Estudios en Historia de la Conciencia de la Universidad de California, Estados Unidos, había emprendido el desarrollo de las primeras páginas electrónicas del EZLN. En pocos meses ese sitio WWW definitivamente había

8. “Comunidad Virtual y Cibercultura. El caso del EZLLN en México", Razón y Palabra, 1998.

9. En diciembre de 1995 , NIC-México sólo consignaba 12 dominios ".gob.mx", de un total de 326 dominios “.mx".

10. Véase: http://ww.inegi.gob.mx/informatica/espanol/informatica.html. 
alentado el desarrollo de una auténtica red mundial de información autónoma sobre el movimiento neozapatista. ${ }^{11}$

Acostumbrados a ejercer en México efectivas formas de presión sobre el desempeño informativo de los medios de difusión convencionales, los responsables de la política internacional y de la comunicación social del gobierno de la República, fueron francamente sorprendidos en un frente inédito para ellos, el de Internet.

Curiosa paradoja de la agonía de un milenio: mientras que el aparato de información de la Presidencia de una nación de casi 100 millones de habitantes, en 1995 realizaba su trabajo careciendo de una elemental estrategia de información y con viejas máquinas de escribir; los neozapatistas, indígenas reales, testimonio de la brutalidad y la existencia de un México profundo, disponían de una compleja y efectiva estrategia informativa en el ciberespacio.

Los simpatizantes del EZLN demostraron una formidable capacidad para difundir en Internet cada comunicado o declaración del subcomandante Marcos. Los miembros de la red de simpatizantes del EZLN desde 1995 traducían cada texto, boletín o comunicado del EZLN a una docena de idiomas, y lo remitían a los principales medios informativos en cuestión de minutos.

La formidable capacidad de respuesta y la notable velocidad adquirida en el manejo de la información en el ciberespacio, contribuyeron a fincar las bases de una generosa simpatía internacional hacia el subcomandante Marcos y hacia el EZLN.

El trabajo que la red de simpatizantes del EZLN ha desarrollado en el ciberespacio, definitivamente contribuyó a fincar buena parte de la gran popularidad internacional del subcomandante Marcos, quien, a pesar del extraño silencio que ha mantenido en los años recientes, continua siendo más conocido en el extranjero que el propio presidente de la República.

Un amplio número de comunidades virtuales han adoptado como suyas las causas y esperanzas sintetizables en todo aquello que representa el EZLN. La atenta mirada que la prensa internacional ha dispuesto hacia Chiapas, definitivamente ha obligado al gobierno a no proceder a partir del recurso de la represión.

Las graves indefiniciones de la administración del presidente Ernesto Zedillo en materia de Internet no sólo admiten considerarse como desafortunados desaciertos en materia de comunicaciones estratégicas del gobierno de México, éstas han trascendido negativamente al plano de la política internacional.

Ante la ausencia de estrategias informativas del gobierno de la República a través de Internet, Laura Sainz, funcionaria del Consulado de México en Nueva

11. Las páginas electrónicas del EZLN pueden consultarse en la siguiente dirección electrónica: http://www.ezln.org. 
York, decidió asumir la responsabilidad de intentar establecer una mínima presencia del gobierno de México en el ciberespacio.

En el sitio www del Consulado de México en Nueva York se difundieron algunos de los principales comunicados que emitió el gobierno de la República durante 1995, e inclusive se publicó en Internet el Primer Informe de Gobierno del Presidente Ernesto Zedillo. Es importante destacar que entonces la Secretaría de Relaciones Exteriores y la Dirección General de Comunicación Social de la Presidencia de la República no disponían de sus respectivos sitios wwW.

Durante ese mismo año y hasta el tercer trimestre de 1996, un asesor de la Dirección General de Comunicación Social de la Presidencia de la República, de apellido Dávila, se abrogó la facultad de publicar en Internet su muy particular versión de páginas WwW del Gobierno de México.

Por absurdo que pudiese parecer, tales páginas electrónicas se encontraban hospedadas en algún servidor que incluía en el dominio el apellido del referido señor Dávila. Además el señor Dávila se dedicó a "dar de alta" esas páginas espurias como supuesto sitio oficial del Gobierno de México en Internet en los principales motores de búsqueda de la red de redes.

También durante 1995, investigadores del Proyecto Internet del Tecnológico de Monterrey, campus Estado de México, dedicaron prácticamente más de diez meses a la tarea de sensibilizar a funcionarios de la Dirección General de Comunicación Social de la Presidencia de la República -entonces a cargo de Carlos Salomón Cámara-, respecto a la importancia de definir apropiadas estrategias de comunicación política para el Gobierno de México a través de Internet, y derivar de éstas el desarrollo de un sitio www para el Gobierno de la República. ${ }^{12}$

En diciembre de 1995 Carlos Almada asumió la Dirección General de Comunicación Social de la Presidencia de la República en sustitución del señor Carlos Salomón Cámara, quien fue designado director de la Lotería Nacional por el presidente Zedillo.

En el mes de junio de 1996, Javier González Rubio, quien llegó a la Dirección General de Comunicación Social de la Presidencia de la República con el equipo de trabajo de Carlos Almada, por recomendación de Miguel Ángel Sánchez de Armas solicitó los servicios del Proyecto Internet del Tecnológico de Monterrey, campus Estado de México, para desarrollar las páginas www de la

12. Uno de los principales factores que explican la lentitud con la cual procedió la Dirección General de Comunicación Social de la Presidencia de la República para decidirse a establecer el sitio WWW de la Presidencia de México, obedece al "manejo intuitivo de la comunicación". Ninguno de los funcionarios que se han desempeñado como responsables de la Dirección General de Comunicación Social de la Presidencia de la República en la administración del presidente Ernesto Zedillo Ponce de León (Carlos Salomón, Carlos Almada y Fernando Lerdo de Tejada) realizó estudios profesionales en el campo de la comunicación. 
Presidencia de la República. De esa manera, el 1ํo de septiembre de 1996 empezó a operar el Sistema Internet de la Presidencia de la República y se publicó ya en su propio sitio www el Segundo Informe de Gobierno del presidente Ernesto Zedillo. ${ }^{13}$

Al establecer su sitio www, la Presidencia de la República despertó el interés de otras dependencias del sector público, las cuales finalmente emprendieron el desarrollo de sus respectivas páginas electrónicas. De acuerdo a información de NIC-México, en eoctubre de 1996 el número de dominios ".gob.mx" ascendió a 63 . Tal cifra representa un incremento de 525 por ciento en el número de dominios ".gob.mx" en el periodo comprendido entre diciembre de 1995 y octubre de 1996.

El Sistema Internet de la Presidencia de la República, subordinado a la Dirección de Publicaciones de la Dirección General de Comunicación Social de la Presidencia, resultó incapaz de poder articular verdaderas estrategias de comunicación institucional para el Gobierno de México a través de Internet.

Los funcionarios responsables del Sistema Internet de la Presidencia en realidad nunca entendieron la necesidad de convertir las páginas electrónicas de la Dirección General de Comunicación Social de la Presidencia de la República en un auténtico sistema de información en línea del gobierno de México.

Mientras que sistemas similares de otras naciones ya desempeñaban útiles funciones de enlace ciudadano, e inclusive contribuían a coordinar las acciones necesarias para enfrentar situaciones de desastre, la ausencia de una auténtica planeación de las acciones comunicativas que habría de cumplir el Sistema Internet de la Presidencia limitó la capacidad informativa del mismo sistema, el cual, carente de una auténtica definición conceptual y de funciones verdaderamente informativas, se limitó a rendir pleitesía a la figura del Presidente.

La rígida estructura temática de las páginas www de la Presidencia de México eliminaba cualquier posibilidad de afirmar y expresar un México amplio, plural y contradictorio. El proyecto comunicativo que se ensayó en las páginas www del gobierno de la República se limitó a consignar y resaltar las acciones, discursos y ceremonias de un solo actor: el presidente de la República. Cualquier cibernauta extranjero que navegue por las páginas www de la Presidencia de la República puede inferir que en México, el único protagonista de la realidad nacional es el presidente Ernesto Zedillo.

13. Las páginas www de la Presidencia de la República fueron hospedadas en un servidor de la empresa Compuserve, multinacional dedicada a ofrecer avanzados servicios en materia de Internet. Esa empresa se encargó de incorporar audio en tiempo real vía Internet en el Tercer Informe de Gobierno del Presidente Ernesto Zedillo. La avanzada tecnología dispuesta por Compuserve, sin duda alguna amortizó la evidente precariedad de contenidos relevantes en el sitio wWw de la Presidencia de República. 
Durante 1997 los sitios www de la Presidencia de la República y de la Secretaría de Gobernación omitieron realizar mención alguna sobre el tema del levantamiento armado en Chiapas. La torpe estrategia de mantener un estricto silencio en el ciberespacio tocó fondo los últimos días de diciembre de 1997. Los lamentables acontecimientos ocurridos el 22 de diciembre en la comunidad de Acteal, municipio de Chenalhó, Chiapas donde el comando paramilitar Máscara Roja ${ }^{14}$ perpetró el asesinato de 45 indígenas tzotziles, ${ }^{15}$ expusieron la gravedad de las insuficiencias informativas del espacio electrónico de la Presidencia de México.

Durante los cinco días inmediatos a la matanza de Acteal, el Gobierno de la República se abstuvo de publicar en Internet cualquier tipo de información relativa a tan lamentables sucesos. Finalmente, la única acción comunicativa que entonces decidió realizar el gobierno de la República en Internet, consistió en reproducir el discurso que el presidente Ernesto Zedillo dirigió a la nación el 27 de diciembre de 1997.

Entre tanto, apenas unos minutos después de haber ocurrido la matanza de Acteal, las páginas www del EZLN ya consignaban las primeras declaraciones del subcomandante Marcos. Los simpatizantes de la causa neozapatista se dedicaron a traducir cada comunicado o boletín de prensa del EZLN a otros idiomas, remitiéndolos a las salas de prensa de los principales medios informativos de todo el mundo.

El gobierno de la República por supuesto que jamás concibió la idea de diseñar una estrategia de información a través de Internet, y su tímida respuesta respecto a la matanza de Acteal se limitó al uso de los medios convencionales.

En la llamada "guerra de tinta e Internet" —como alguna vez calificó José Ángel Gurría, responsable de la Secretaría de Relaciones Exteriores, al levantamiento armado en Chiapas-, el gobierno de la República perdió una importante batalla de información en el ciberespacio.

El torpe desempeño informativo que observó en Internet el gobierno de la República ante los lamentables acontecimientos de Acteal, evidenció que los estrategas y asesores de Zedillo en realidad todavía no conseguían entender el hecho de que Internet ya contribuía decisivamente a la formación de la opinión pública internacional, incidiendo particularmente en la formación de opiniones y representaciones colectivas de los llamados sectores "sensibles".

Los primeros días de 1998, la Secretaría de Gobernación emprendió el rediseño de sus páginas electrónicas, las cuales incorporaron un apartado temático en el cual el gobierno de la República finalmente decidió exponer en

14. Véase: http: //spin.com.mxx floresu/fzln/archivo/paramilitares/mascara.roja.htm.

15. Los nombres y edades de cada una de las víctimas de la matanza pueden consultarse en: http://spin.com.mx floresu/fzln/archivo/matanza.de.acteal/home.html. 
Internet su postura respecto al conflicto en Chiapas y el EZLN. Además, se presentaron obligados relevos en el Sistema Internet de la Presidencia. ${ }^{16}$

Las páginas Www de la Secretaría de Gobernación actualmente dedican dos ıpartados al tema de Chiapas y al EZLN en las secciones "Lo nuevo en:" y “Cobertura Especial". Las páginas www de la Presidencia de la República ya ncluyen un apartado sobre el conflicto en el estado de Chiapas, el cual lleva por ítulo: "Chiapas, Sección Especial".

Las páginas wWw de iYa Basta!, además de incluir información relativa al छZLN y a la situación existente en Chiapas dedican un amplio apartado a la natanza de Acteal, bajo el título: “iActeal no se olvida!" Del referido apartado ;e desprenden tres secciones: "Matanza de Acteal", "Declaración del EZLN a ropósito del Libro Blanco sobre Acteal", "Informe especial del Centro de Derechos Humanos Fray Bartolomé de las Casas: Acteal entre el duelo y la ucha".

Internet impone un nuevo mundo de información y desplaza consigo una aueva esfera política: la internetacional. El mundo resultante dispone de una tensidad insospechada en sus comunicaciones y viene acompañado de nuevos mercados emergentes, nuevos productos y, por supuesto, nuevos problemas. Ningún Estado está en condiciones de poder controlar o limitar en este preciso instante la increíble apertura que registra el intercambio de información a nivel internetacional.

En México el desafío de Internet de ninguna manera limita sus repercusiones al estricto ámbito de la política interior o la política internacional. Es indispensable entender que el tema de Internet en realidad se inscribe en una discusión mucho más amplia: la democracia de nuestra sociedad y el derecho a la información.

\section{No esperes que sea tu amigo}

Además de que la actual administración ha procedido sin estrategia alguna en materia de Internet y de forma siempre reactiva a los acontecimientos, situación que fácilmente puede advertirse en las titubeantes acciones que hemos referido, las intromisiones de grupos organizados de "crackers"17 de alguna manera con-

16. Precisamente de esos cambios se desprendió el nuevo concepto de diseño que presentan las páginas WWW de la Presidencia de la República, las cuales prácticamente conservan intacta la anterior estructura de contenidos, subordinada al propósito de rendirle pleitesía a la figura del Ejecutivo.

17. Al igual que los "hackers", la comunidad de crackers se extiende por todo el mundo. Algunos antropólogos de la red los describen como hábiles programadores, generalmente adolescen- 
tribuyeron a obstruir el desarrollo de una verdadera política de comunicaciór social en Internet por parte del Gobierno de la República.

A partir de 1998 los sitios WwW de algunas instituciones gubernamentale: fueron objeto de frecuentes ataques de grupos organizados de crackers. Por ta motivo, algunos reconocidos periodistas, como Raúl Trejo Delarbre, han afirma. do que tales acciones posiblemente formen parte de una conspiración contra e. gobierno de Zedillo, en la cual inclusive podrían estar involucrados crackers profesionales. ${ }^{18}$

Por otra parte, expertos en el campo de la informática, como Miguel d $\epsilon$ Icaza, han restado la importancia de los ataques que han cometido grupos organizados de crackers contra servidores wwW de instituciones gubernamenta. les. Miguel de Icaza afirma que los actos de los crackers de ninguna manera corresponden al desarrollo de una ciberguerrilla. Se trata de "niños que estár. jugando a los tecnopiratas, cuyo propósito primordial simplemente consiste er. adquirir cierta notoriedad ante la opinión pública". ${ }^{19}$

El 4 de febrero de 1998, "X Ploit Team", grupo de crackers que se jacta de ser "orgullosamente mexicano", reemplazó el logotipo oficial de la Secretaría de Hacienda por algunas de las imágenes más conocidas del carismático lídeı revolucionario Emiliano Zapata, incorporando en la página principal de Hacienda la siguiente leyenda: "Nuestra afiliación no es ninguna, no pertenecemos a] EZLN, pero éste es nuestro derecho de libre expresión como mexicanos". ${ }^{20}$ Ese fue el mensaje de bienvenida que le deparó "X Ploit Team" a José Ángel Gurría, quien por esas fechas había asumido la titularidad de la Secretaría de Hacienda.

tes, quienes aspiran a ser reconocidos públicamente como "hackers". Sin embargo, a diferen. cia de la manifiesta generosidad de la comunidad que representa su perfecto modelo, los "crackers" de ninguna manera asumen el compromiso de aportar su incuestionable talento al mejoramiento de la red de redes y, para llamar la atención de la opinión pública o el reconocimiento de los mismos "hackers", frecuentemente irrumpen espectacularmente en sitios WWW, violando los costosos dispositivos de seguridad que han dispuesto instituciones y empresas como Microsoft, Coca Cola, el Pentágono, la CIA, el FBI, el Congreso de los Diputados de España, el Banco Sakura (Japón) y la NASA, entre muchos otros. En algunas ocasiones los "crackers" no se conforman con reemplazar las principales páginas del sitio WWW al que penetraron sino que se dedican a extraer aquella información que pudiese ser considerada valiosa por las instituciones o empresas que han sido objeto de sus ataques. Mediante la extracción de bases de datos, por ejemplo, los "crackers" pueden obstruir las operaciones de la organización que fue blanco de sus agresiones. Al amparo del anonimato, algunos de los sujetos que aspiran a ser reconocidos como "crackers", se prestan a participar en campañas de difamación contra personajes públicos, o se involucran en auténticas acciones delictivas, las cuales en ocasiones comprenden desde actos de terrorismo, chantaje y
acoso sexual.

18. Véase: http://www.2600.com.

19. Véase: "Lagunas legislativas restan seguridad a Internet; las páginas del gobierno son inva20. Ídem. 
Durante 1998 los miembros del "X Ploit Team" realizaron frecuentes intromisiones en sitios www del Gobierno de la República. Los ataques del señalado grupo de crackers comprendieron las páginas wwW del Instituto Nacional de Estadística, Geografía e Informática (INEGI), la Comisión Nacional del Agua, el Senado de la República y la Secretaría de Salud.

En cada una de las intromisiones efectuadas a los sitios WWW de las referidas instituciones gubernamentales, los integrantes de "X Ploit Team" incorporaron mensajes alusivos a sus acciones como supuestos hackers, así como textos propagandísticos en favor del EZLN y, en algunos casos, ligas hacia las páginas electrónicas del EZLN.

Además los integrantes de "X Ploit Team" emitieron varios comunicados de prensa, en los cuales se atribuyeron la responsabilidad de haber realizado algunas alteraciones a las páginas electrónicas de las citadas dependencias.

$\mathrm{El}$ ataque que cometieron los integrantes de "X Ploit Team" a las páginas www del Senado de la República ocurrió la madrugada del lunes 25 de mayo de 1998. En tal intromisión, el citado grupo de crackers no se limitó a modificar las imágenes y la información contenida en las páginas www del Senado de la República, además emprendió violentas agresiones al servidor que hospedaba las páginas www del Senado. 21

Ese día, alrededor de las 8 de la mañana, el personal del Proyecto Internet del Tecnológico de Monterrey, campus Estado de México, responsable del desarrollo de las páginas WWW del Senado de la República se percató de que la página principal del www del Senado había sido modificada, incorporándose en ésta la imagen de la "Senadora Yessica Rabbit".

Desde las instalaciones del Tecnológico de Monterrey, campus Estado de México, se procedió a restituir de forma remota la página principal del www del Senado de la República. A tal acción sucedió un nuevo ataque de "X-Ploit Team", el cual causó graves daños al servidor en el cual se hospedaban las páginas del Senado de la República. ${ }^{22}$

Como en ese servidor también se administraban los servicios de correo electrónico de los senadores, "X-Ploit Team"afirmó haber introducido un sni-

21. Los sistemas dedicados al almacenamiento de la información que admite considerarse como crítica lógicamente deben ser los más seguros. En algunas naciones - Singapur, por ejemplo-, la seguridad computacional ya admite el carácter de un importante asunto de seguridad nacional.

22. Es necesario aclarar que la Dirección de Informática del Senado de la República se encontraba a cargo de la administración del servidor WWw del Senado de la República, y que a partir del atentado cometido por "X Ploit Team" el Senado de la República celebró un nuevo contrato con el Tecnológico de Monterrey, campus Estado de México. Así un equipo de expertos en seguridad computacional, coordinado por el doctor Jesús Vázquez, asesoró al Senado en materia de seguridad computacional. 
ffer, ${ }^{23}$ con el cual se atribuyó haber obtenido correspondencia sumamente comprometedora de algunos de los senadores de la República.

Además de obtener información confidencial de las organizaciones o empresas que desafortunadamente son blanco de sus agresiones, las acciones de los crackers también suelen obedecer al propósito de sembrar confusión y desaliento en las instituciones o empresas agredidas, haciéndoles sentirse inseguras, expuestas y sumamente vulnerables.

De ninguna manera las acciones de los crackers se limitan a los sitios WwW del sector público. También los sitios www de instituciones financieras como Bancomer; instituciones educativas como el Instituto Politécnico Nacional, distintos campus del Tecnológico de Monterrey; así como microempresas y organizaciones no gubernamentales han resentido frecuentes ataques de grupos organizados de crackers, quienes, como hemos señalado, no siempre se limitan a pregonar su objetable protagonismo por haber consumado determinadas alteraciones al contenido de la página principal de alguna institución; también acostumbran extraer información interna de las instituciones o empresas agredidas, la cual les permitiría cometer delitos que ni siquiera aún se consideran posibles en nuestro imaginario legislativo. ${ }^{24}$

23. Un "sniffer" o "husmeador" es un programa que se introduce en una red para "olfatear" toda la información que los usuarios de la red pongan en circulación en el ciberespacio. El "sniffer" es capaz de inferir inteligentemente aquellos datos que permiten obtener los passwords de seguridad de los usuarios de la red. Tal información lógicamente podría destinarse a la comisión de un sinnúmero de delitos de "cuello blanco". Para enfrentar la amenaza de los "husmeadores", algunas empresas y gobiernos - como el de Estados Unidos- han desarrollado avanzados sistemas de criptografía, los cuales permiten codificar los datos y proteger así la información. La criptografía con clave pública (Public Key Encription) fue descubierta en 1975 por Whitefield Diffie. Entre los principales procedimientos orientados a la seguridad computacional destacan: dispositivos físicos, tales como cerraduras, identificaciones, puertas y sensores; personal de seguridad dedicado al registro y monitoreo de los espacios en los cuales residan los servidores que almacenen la información que admita considerarse como crítica; procedimientos de seguridad administrativa, tales como investigación de negligencias, desobediencia a las normas de seguridad; data/Información: control del acceso y la reproducción de ésta; seguridad online: fire-walls.

24. El comportamiento de los crackers sin duda alguna afectan el desarrollo de las organizaciones, pues las condiciona a tener que realizar cuantiosas y constantes inversiones en materia de seguridad computacional. El monto destinado a la adquisición de vacunas, software y hardware de seguridad suele ir en proporción de la misma "sensación de seguridad" que pretenda establecer la empresa. Desafortunadamente ninguna empresa nunca estará cien por ciento segura de no ser blanco de posibles ataques de lo crackers. Las acciones de los crackers que irrumpen en sitios wwW definitivamente admiten tipificarse como delitos, pues violan los derechos de confidencialidad e intimidad informática, así como los derechos de propiedad intelectual sobre la información contenida en los servidores afectados por la acción de los crackers. Es importante destacar que no todas las intromisiones a un sistema de información se realizan en línea. Entre las intromisiones más comunes destacan: 1 . Accesos no autorizados o penetración: el usuario no autorizado obtiene acceso a un sistema, o una persona autorizada a usar el sistema para un determinado fin lo usa para otro ajeno. 2. Implantación: el 
El impresionante desarrollo que ha alcanzado Internet ha generado nuevos dilemas éticos y sociales, los cuales, sin duda alguna, necesitan ser resueltos. Confiar en que la anarquía de la red de redes algún día podrá derivar de su misma necesidad de autorregularse el equilibrio necesario para Internet, parece un argumento sumamente ingenuo. La necesidad de contener y limitar de alguna forma, en cambio, es inmediata y enorme.

En el verdadero sentido de la palabra, la información que circula por medio de Internet es segura ante la eventualidad de algún ataque nuclear. Ese precisamente fue el propósito primordial del Advanced Research Project Agency, el cual en el año de 1967 creó Arpanet, una red de trabajo originalmente diseñada para la experimentación militar de tecnologías de telecomunicaciones informáticas, la cual garantizó que, ante la eventualidad de un ataque nuclear por parte de alguna de las potencias enemigas a los Estados Unidos, la información que se considerase como estratégica para el gobierno de Estados Unidos no pudiera extraviarse. Arpanet es el antecedente directo de Internet.

De lo anterior, Gerhard Schweigler deduce que la información que circula en Internet no sólo está protegida de ataques nucleares, también dispone de complejas defensas contra la censura que pudiesen pretender imponer algunos organismos, ya que el flujo de información que circula en la red, de ninguna manera puede ser detenida en un determinado punto contra la voluntad del emisor o del receptor. ${ }^{25}$

Internet es un medio paradójico: debe su surgimiento a la necesidad de preservar la red militar de la principal potencia mundial de eventuales ataques nucleares de sus enemigos; y deriva en una solidaria red internacional, anárquica y descentralizada.

Los nuevos servicios que se desprenden de Internet de ninguna manera se inscriben en un vacío jurídico. Lo que es punible offline también debe ser sancionable online. Por tal motivo, el destacado investigador Ernesto Villanueva, atinadamente sostiene que "las libertades de expresión e información no son absolutas, sino que están limitadas por una serie de bienes jurídicos protegidos, entre ellos el orden público, la vida privada y la moral social". ${ }^{26}$

Es indispensable reparar en la necesidad de legislar en materia de Internet con el firme propósito de inhibir el desarrollo del considerable número de

invasor se introduce al sistema para dejar un mecanismo que le facilitará realizar posteriores ataques, como, por ejemplo, un "Caballo de Troya". 3. Espionaje: el invasor obtiene información confidencial sin penetrar necesariamente a la computadora.

25. Gerhard Schweigker: "Política Internacional: ¿Un mundo feliz?", en Josef Thesing y Frank Priess (eds.): Globalización, Democracia y Medios de Comunicación. Konrad Adenauer Stiftung, Argentina, 1999.

26. Véase Ernesto Villanueva: "Límites jurídicos de la libertad informativa en la red de redes", Medios, Suplemento de El Nacional. Número 3, 12 de abril, 1998, página IV. 
prácticas ilícitas que actualmente se realizan a través de la red, como los llamados "delitos de cuello blanco", así como reprobables manifestaciones de discriminación e intolerancia racial, étnica, cultural, social, política y religiosa que practican en la red un amplio número de grupos extremistas. ${ }^{27}$

En 1986, Richard Mason publicó el artículo "Cuatro aspectos éticos de la era de la información". ${ }^{28}$ Mediante el acrónimo PAPA Mason presentó cuatro grandes áreas temáticas relativas a la reflexión ética y deontológica que debe acompañar el desarrollo de las nuevas tecnologías de información. El acrónimo PAPA procede de los siguientes ejes temáticos: privacy (intimidad y vida privada), accuracy (exactitud), property (propiedad) y access (acceso).

\section{Intimidad}

En Internet, como en la mayor parte de los medios de difusión colectiva, suele no repararse en la importancia que admiten las esferas "vida pública", "vida privada" y "vida íntima", tanto en términos informativos como en criterios de publicidad.

El concepto intimidad supone interioridad y, por definición, es contrario y opuesto a las esferas de lo público y de la publicidad (Jürgen Habermas). La intimidad incluso comprende una dimensión todavía mucho más profunda que la esfera misma de la "vida privada", pues corresponde, en términos psicoanalíticos, al "sentimiento yóico".

La intimidad debe ser asociada a la confidencialidad. La "vida íntima" no sólo no debe ser divulgable. Ni siquiera es admisible suponer la posibilidad de investigarla. Sin embargo, algunos usuarios de la red de redes han generado gran incertidumbre al hacer públicas sus "vidas íntimas" mediante el empleo de las llamadas webcams. Mediante esas expresiones de exhibicionismo, las fronteras existentes en cada una de las diferentes esferas parecen diluirse, afirmándose el imperio de los espacios públicos y la publicidad de los espacios íntimos y privados. ${ }^{29}$

Las avanzadas tecnologías de información además pueden operar como un complejo dispositivo panóptico, realizando funciones de vigilancia y de castigo. ${ }^{30}$ Las webcams que actualmente ofrecen útil información sobre el estado de la vialidad en la ciudad de México en las páginas www de Prodigy, ${ }^{31}$ fácilmente

27. Una de las primeras contribuciones en la materia lo representa el trabajo de Gabriela Barrios Garrido, Marcia Muñoz de Alba y Camilo Pérez Bustillo: Internet y derecho en México, McGraw Hill, 1998.

28. Citado por Inger V. Erickson en el capítulo "Computers or Humans: Who are in control", Kizza, Joseph Miga (ed.). Social and Ethical Effects of the Computers Revolution. McFarland \& Company Publishers, Jefferson, Carolina del Norte y Londres, 1996, páginas 87 y 88.

29. Véase: http://www.krosnosf.com.

30. Véase Michel Foucault: Vigilar y castigar. Siglo XXI Editores, México. 
podrían erigirse como complejos dispositivos panópticos del Big Brother, el cual, - remember George Orwell - estaría en condiciones de poder vigilar todo y a todos por medio de un sistema televisivo omnipresente, que simultáneamente podría realizar tareas de propaganda y control.

El considerable número de formularios y solicitudes en las cuales voluntariamente proporcionamos información personal para el ingreso a instituciones educativas, la realización de chequeos médicos, solicitud de seguros, pago de impuestos y préstamos diversos han sido aprovechados por distintas empresas dedicadas a traficar bases de datos, las cuales también suelen elaborar perfiles socio económicos y socio culturales de los consumidores.

De ese tipo de empresas precisamente procede una buena parte de la correspondencia indeseable que diariamente recibimos en nuestras cuentas de correo electrónico y que representan una invasión a nuestra privacidad.

\section{Exactitud}

Una considerable cantidad de la información que circula a través de Internet puede ser calificada de dudosa u objetable, el término que suele describir ese desprecio a Internet es: explosion of nonsense.

Tal señalamiento precisamente ha sido adoptado por recalcitrantes generaciones de viejos académicos, quienes proceden a descalificar la totalidad de la información que circula en Internet, afirmando que ésta carece de valor y significado.

Otros críticos advierten una estrecha relación entre la "mundialización de los mercados" y la "mundialización de las redes de información” y, resucitando las tesis del "arrepentido Louis Althusser", denuncian a Internet como un aparato ideológico del neoliberalismo, dedicado a legitimar y promover el $A m e$ rican Way of Life a la velocidad de la luz, prescindiendo de la memoria humana y anulando la historia y especificidad misma de las naciones.

Pese a las críticas y cuestionamientos de sus detractores, hoy Internet es la forma más rápida y sencilla de facilitar y obtener información pues, como afirma Gerhard Schweigker:

Si inicialmente hubo algunas dudas en cuanto a la utilidad de la red (se hablaba de pocas informaciones útiles, mucha anarquía y poca sistematización), hoy ha desarrollado una dinámica propia que hace que los gobiernos, empresas, asociaciones, universidades, instituciones científicas y los propios medios clásicos ya no puedan estar ausentes en la red. Al mismo tiempo, buscadores cada vez más sofisticados y

31. Véase: http://www.prodigy.com.mx. 
exactos facilitan los medios necesarios para que el usuario pueda orientarse en una avalancha de datos. ${ }^{32}$

Internet supone en sí mismo el ejercicio y el desarrollo de la autología; es decir, la autoaplicación del conocimiento y el conocimiento aplicado al conocimiento. Tal situación ha permitido descubrir nuevas herramientas de comunicaciones y nuevos usos.

Las comunidades sensibles de Internet velan por mantener siempre abierta la libertad de la oferta de información en la red. La formidable explosión de contenidos y la disponibilidad de la más amplia oferta de información y entretenimiento en Internet, obligan a cuestionarse sobre la forma en la cual se está construyendo la percepción social de la realidad de las nuevas generaciones.

De ninguna manera pretendemos parecer apocalípticos adjudicándole a Internet perversidades similares a la que un amplio número de investigadores de la academia latinoamericana de comunicación encontraron, tanto en el "Pato Donald" como en el Atari y Nintendo. Creemos que tan elemental expresión de intolerancia de ninguna manera contribuye a comprender la complejidad del universo y pluralidad informativa de Internet.

Porfirio Barroso afirma que la mayor parte de los códigos en los cuales se aborda el tema de la exactitud, concluye que los profesionales de la informática deben ser claros, exactos, objetivos, imparciales, independientes en su quehacer cotidiano y en la transmisión de la información o, por el contrario, no deben transmitir información falsa, incorrecta, exagerada, manipulada, equivocada, partidista o inexacta. ${ }^{33}$

Los buenos propósitos por sí mismos resultan insuficientes para contener a Internet así como las acciones aisladas de algunas naciones. Simplemente cabe recordar que los esfuerzos realizados por los legisladores estadounidenses que pretendían impulsar la llamada Communications Decency Act (CDA) fueron un verdadero fracaso en lo relativo al establecimiento de formas de censura a determinados contenidos en Internet.

Las Naciones Unidas y la UNESCO ya han redactado un código de fundamentos éticos sobre la responsabilidad periodística, el cual podría extenderse y adaptarse a Internet. Sólo una generosa iniciativa internacional podrá establecer regulaciones en Internet.

32. Gerhard Schweigker, op cit., p. 366.

33. Véase Porfirio Barroso Asenjo y Jesús María Vázquez: Deontología de la informática. Instituto de Sociología Aplicada, Madrid, 1993. 


\section{Propiedad}

Gerhard Schweigler afirma que: "Internet no reconoce fronteras y plantea los viejos dilemas de la libertad de expresión personal y la necesidad de control estatal bajo una nueva forma y en una dimensión internacional". ${ }^{34}$

Toda información publicada en algún sitio de la www puede "bajarse" desde cualquier punto de la red. Si bien es posible establecer algunas barreras de carácter tecnológico para impedir que sea consultada determinado tipo de información, también es perfectamente posible eludir las restricciones impuestas por los dispositivos de control. Además de la necesidad de legislar los derechos de autor sobre el software y el hardware es indispensable reparar en la necesidad de cuidar la propiedad intelectual de los contenidos.

\section{Acceso}

Algunos críticos de Internet afirman que se trata de un medio elitista que introduce una nueva y profunda división social. De acuerdo con la NUA Internet Surveys, en septiembre de 1999 la población mundial que ya tenía acceso a Internet apenas ascendía a 201 millones de personas. El siguiente cuadro presenta la distribución regional de los usuarios de la red de redes. ${ }^{35}$

\begin{tabular}{|l|c|}
\hline \multicolumn{1}{|c|}{ Región } & Millones de usuarios \\
\hline África & 1.72 \\
\hline Asia/Pacífico & 33.61 \\
\hline Europa & 47.15 \\
\hline Medio Oriente & 0.88 \\
\hline Canadá y Estados Unidos & 112.4 \\
\hline América Latina & 5.29 \\
\hline
\end{tabular}

La mayor parte de los usuarios de la red de redes efectivamente procede de los sectores que cuentan con mayores niveles de escolaridad y de mejor posición económica.

Internet, medio de comunicación que admite el calificativo de "inteligente", particularmente es popular entre las generaciones jóvenes, las cuales han aprendido a valorar sus posibilidades y dominar los lenguajes de sus múltiples herramientas de comunicaciones en los recintos universitarios. 
Respecto al número de usuarios de Internet en México, NUA Internet Surveys consigna las siguientes cifras:

\begin{tabular}{|l|l|c|}
\hline \multicolumn{1}{|c|}{ Fecha } & \multicolumn{1}{|c|}{$\begin{array}{c}\text { Empresa responsable de } \\
\text { la investigación }\end{array}$} & $\begin{array}{c}\text { Total de usuarios } \\
\text { de Internet en } \\
\text { México }\end{array}$ \\
\hline Septiembre de 1999 & VISA & 900,000 \\
\hline Abril de 1999 & Llavín & 600,000 \\
\hline Diciembre de 1998 & IDC & 713,000 \\
\hline Diciembre de 1998 & Mori de México & 504,900 \\
\hline Noiviembre de 1997 & CommerceNet Research & 370,000 \\
\hline
\end{tabular}

Para extender el uso de Internet en amplios sectores de nuestra sociedad, los proveedores de acceso a Internet en los últimos años han reducido significativamente las cuotas mensuales por el servicio de conexión a Internet, incorporando atractivos planes que además contemplan la adquisición de avanzado equipo computacional, como es el caso de Telmex.

Ese tipo de acciones han incrementado considerablemente el número de computadoras que se destinan al hogar, en proporción inclusive superior al crecimiento porcentual observado en la adquisición de equipo computacional por parte de los sectores educativo y gubernamental.

Una de las principales metas de la administración del presidente Bill Clinton consistió en garantizar la presencia de por lo menos una computadora conectada a Internet en cada aula de toda escuela de educación elemental de la Unión Americana. Los futuros retos de la educación suponen el desarrollo de escuelas cableadas y sistemas de aprendizaje en línea.

El gobierno de la República deberá asumir conscientemente el rol de natural proveedor de útil información ciudadana $y$, para decididamente impulsar el desarrollo educativo del país impulsar el desarrollo de una alianza estratégica con las principales universidades del país, a fin de garantizar el mayor número posible de condiciones de acceso a Internet a un mayor número de mexicanos.

Además el gobierno de la República deberá definir estrategias orientadas a estimular la capacidad exportadora de las micro, pequeñas y medianas empresas, las cuales generan el mayor número de fuentes de empleo en el país.

\section{Stairway to heaven}

Las graves insuficiencias legislativas en materia de Internet no sólo indirectamente han estimulado la reprobable impunidad de los crackers, lo verdadera- 
mente grave del asunto radica en que el vacío legislativo ha inhibido el desarrollo del comercio electrónico en México.

Muchas de las empresas extranjeras que actualmente pueden realizar operaciones comerciales con empresas mexicanas a través de Internet, desechan la posibilidad de hacerlo dada la incertidumbre legislativa que prevalece en México en materia de comercio electrónico, optando por concretar sus operaciones comerciales con las empresas de aquellas naciones que ya han legislado el desarrollo de prácticas comerciales a través de Internet.

La mayor parte de los especialistas en materia de Internet y comercio electrónico coincide en estimar que en el año 2003, fecha en la cual seguramente se habrá consumado la fusión de Internet y la televisión, las ventas que se realizarán a través de la red de redes alcanzarán cifras de trillones de dólares. La firma de consultoría ActivMedia considera que en el año 2003 se realizarán ventas por 1.3 trillones de dólares. ${ }^{36}$ En cambio la empresa de consultoría Forester Research estima que en el año 2003 las ventas por Internet ascenderán a 3.2 trillones de dólares. ${ }^{37}$

A pesar del sostenido incremento que registraron los dominios .com.mx y del considerable número de portales y comercios que iniciaron operaciones comerciales en línea durante 1999 -sosteniendo la gran mayoría cuantiosas pérdidas-, el desarrollo del comercio electrónico en México todavía admite ser considerado como incipiente.

El gobierno del presidente Ernesto Zedillo no sólo se ha mostrado incapaz de poder definir una estrategia definida en materia de comunicación social a través de Internet, también se ha mostrado incapaz de poder articular una estrategia definida en materia de comercio electrónico. En ambas asignaturas la administración del doctor Zedillo francamente ha reprobado.

El Banco Nacional de Comercio Exterior (Bancomext) ha pretendido afirmarse como la instancia gubernamental que de forma más definida se propone intervenir en el desarrollo del comercio electrónico en México, intentando

36. Moira Jacobs: "International E-Business Oportunities and Challenges: A Smal Business Perspective". Ponencia presentada en The 1999 e-Business Opportunities, Challenges, and Winning Strategies. Universidad de Montana en Missoula y The Montana World Trade Center, Estados Unidos, 2-5 de agosto de 1999. Es importante señalar que Moira Jacobs funge como responsable directa de más de 100 centros que dependen del Departamento de Comercio de Estados Unidos, dedicados a estimular la capacidad exportadora de las micro, pequeñas y medianas empresas estadounidenses. Esos centros proporcionan servicios integrales de consultoría en materia de Internet y comercio electrónico a las empresas estadounidenses interesadas en exportar.

37. Vadim Levtin: “Getting Started in Cyperspace: Reviewing the Basics". Ponencia presentada en The 1999 e-Business Conference, Universidad de Montana en Missoula y The Montana World Trade Center, Estados Unidos, 2-5 de agosto de 1999. 
ofrecer, además de un portal, soluciones integrales a las empresas mexicanas exportadoras.

Si el Banco Nacional de Comercio Exterior se propone regular el desarrollo del comercio electrónico en México, el fracaso de tal iniciativa ya es previsible, pues paralelamente y con mayores recursos destinados a la mercadotecnia y a la promoción de sus portales, bancos, medios de comunicación y empresas interesadas en el negocio de la telefonía ya ofrecen soluciones integrales en materia de comercio electrónico a las micro, pequeñas y la medianas empresas, a diferencia de Bancomext, institución que sólo considera en sus planes de comercio electrónico a las empresas mexicanas que ya disponen de una sólida capacidad exportadora.

Además muy poco se ha avanzado en la discusión de una legislación apropiada para regular el desarrollo de operaciones comerciales en México, la cual habría de contemplar un considerable número de reformas a los códigos civil, penal y mercantil.

Aún cuando parece razonable considerar la necesidad de consagrar en nuestra Constitución el respeto a la intimidad informática, así como establecer normas y procedimientos que garanticen su efectiva protección a través de medios como Internet - como atinadamente destaca Ernesto Villanueva, nuestra máxima autoridad en el campo de la reglamentación al derecho a la información-, la aparente indiferencia legislativa hacia Internet y el desarrollo del comercio electrónico solamente puede explicarse como torpe reflejo del mismo razonamiento de quienes se proponen cancelar toda iniciativa tendiente a reglamentar el derecho a la información, consagrado en los artículos sexto y séptimo de nuestra Constitución.

Mientras que otras naciones - Singapur, por ejemplo- ya han definido estrategias concretas en materia de Internet y comercio electrónico, incorporándolas a sus respectivos planes de desarrollo, en México el tema del comercio electrónico ni siquiera admite mención alguna por parte de los candidatos a la Presidencia de la República. El próximo gobierno deberá recuperar a pasos agigantados el tiempo que ya se ha perdido, y se verá en la necesidad de definir estrategias de comunicación y desarrollo en materia de Internet y comercio electrónico.

\section{Bibliografía}

Almino, Jao (1986): La edad del presente. Tiempo, autonomia y representación en la política. Fondo de Cultura Económica, México.

Anderson, Ralph E.y Carter, Irl (1994): La conducta humana en el medio social. Enfoque sistémico de la sociedad. Gedisa, Barcelona, España. 
Balandier, Georges (1994): El poder en escenas. De la representación del poder al poder de la representación. Paidós, Barcelona.

Barrios, Garrido et al. (1998): Internet y derecho en México, Mc Graw Hill, 1998.

Barroso, Asenjo y Vázquez, Jesús María (1993): Deontología de la informática. Instituto de Sociología Aplicada, Madrid.

Bonfil Batalla, Guillermo (1987): México profundo. Una civilización negada. CIESAS-SEP, México.

Bruner, Jerome (1988): Realidad mental y mundos posibles. Gedisa, Barcelona. Breton, Philippe y Proulx, Serge (1990): La explosión de la comunicación. Civilización, Barcelona.

Boserup, Ester (1984): Población y cambio tecnológico. Crítica, Barcelona.

Cardwall, Donald (1996): Historia de la tecnología. Alianza Universidad, Madrid.

Curran, James et al. (1981): Sociedad y comunicación de masas. FCE, México.

Davis, Stan y Meyer, Christopher (1999): Blur, the Speed of Change in the Connected Economy, Ernst \& Young Center for Business Innovation, Ed Warner Books.

Dery, Mark (1998) Velocidad de escape. La cibercultura en el final del siglo. Ed. Siruela, Madrid.

Dormido Bencomo, Sebastián et al. (1995): Sociedad y nuevas tecnologías. Trotta, Madrid, España.

Esteinou Madrid, Javier (1989): Hacia la primavera del espíritu nacional, Propuesta cultural para una nueva televisión mexicana. Fundación Manuel Buendía, México.

Fernández, Christlieb, Fátima (1982): Los medios de difusión masiva en México. Juan Pablos, México.

Flores Olea, Víctor y Gaspar de Alba, Rosa Elena (1998): Internet y la revolución cibernética, México.

Forester, Tom (1992): Sociedad de alta tecnología. Siglo XXI Editores, México. Foucault, Michel (1983): Vigilar y castigar, Siglo XXI Editores, México.

Gates, Bill (1999): Business @the Speed of Thought. Using a Digital Nervous System. Warner Books, Estados Unidos.

Giddens, Anthony (1995): La constitución de la sociedad. Bases para la teoría de la estructuración. Amorrortu, Buenos Aires.

Gruzinski, Serge (1995): La guerra de las imágenes. De Cristóbal Colón a "Blade Runner". FCE, México. 
Harmon L. Royarmon (1996): Reinventing the Business. The Free Press, New York.

Kizza, Joseph Miga (ed.) (1996): Social and Ethical effects of the Computer Revolution. McFarland \& Company Publishers, Jefferson, Carolina del Norte y Londres.

Landow, George P. (1995): Hipertexto. La convergencia de la teoría crítica contemporánea y la tecnología, Paidós, Barcelona.

Luhmann, Niklas (1991): Sistemas sociales. Lineamientos para una teoría general. Universidad Iberoamericana-Alianza Editorial, México.

McLuhan, Marshall (1969): La comprensión de los medios como las extensiones del hombre. Diana, México.

Negroponte, Nicholas (1996): Ser digital. Atlántida-Océano, México.

Odum, Eugene P. (1992): Ecología: bases científicas para un nuevo paradigma. Vedrá, Barcelona.

Postman, Neil (1993): The Surrender of Culture to Technology, New York Press, Nueva York.

Piscitelli, Alejandro (1995): Ciberculturas. En la era de las máquinas inteligentes, Paidós, Barcelona.

Queau, Philippe (1995): Lo virtual. Virtudes y vértigos. Paidós, Barcelona.

Scott Morton, Michael (1991): The Corporation of the 1990's Information Technology and Organizational Transformation, Oxford University Press.

Senn A. James (1998): Análisis y diseño de sistemas de información, McGraw Hill, México.

Sluski, Carlos E. (1996): La red social: fronteras de la práctica sistémica. Gedisa, Barcelona.

Tapscot, Don y Caston, Art (1993): Paradigm Shift: The New Promise of Information Technology, McGraw Hill, Nueva York.

Thompson, John B. (1993). Ideología y cultura moderna. Teoría crítica social en la era de la comunicación de masas, UAM-X, México.

Von Foerster, Heinz (1991): Las semillas de la cibernética. Gedisa, Barcelona. Wagensberg, Jorge (1994): Ideas sobre la complejidad del mundo. Tusquets, Barcelona.

Wiener, Norbert (1985): Cibernética. Tusquets, Barcelona. 